\title{
Esclavitud en la Extremadura del siglo XVI
}

\author{
José Antonio Ballesteros Díez \\ UNED. MÉRIDA
}

Slavery in Extremadura during the Sixteenth Century

\begin{abstract}
RESUMEN ABSTRACT
La presencia de esclavos durante el siglo $X V I$ era un hecho tan generalizado en Extremadura como en el resto de Castilla. El conocimiento de este grupo social está diluido entre los marginados o los de ilegítimos, por lo que se hace una aproximación para establecer en distintos lugares de la región algunos datos cuantitativos que permitan medir su participación en el conjunto de la sociedad.

PALABRAS CLAVE: esclavitud / siglo XVI / Extremadura

The presence of slaves during the Sixteenth Century was a general fact both in Extremadura and in the rest of Castilla. The knowledge of this social group was diluted between the dropouts or the descendents of the illegitimate, therefore we are going to make an approach to establish in different places of the region some quantitative data which allow to measure their participation in the whole of the society.

KEYWORDS:

slavery / Sixteenth Century / Extremadura
\end{abstract}

El conocimiento historiográfico del fenómeno de la esclavitud ha sido, en gran medida, perjudicado por el historicismo, pues la fragmentación cronológica de la Historia, según las convencionales Edades, cuyos respectivos hitos de principio y final están referidos a determinados acontecimientos de carácter marcadamente singular y político, desplazaba al esclavismo, en la perspectiva histórica, a unos lugares alejados de los primeros planos y, con frecuencia, mezclado con otros grupos sociales formando el conjunto que conocemos como de los marginados sociales. El hecho de que la esclavitud existiera desde la Antigüedad hacía que ésta no fuera un hecho histórico nuevo, y que su pervivencia de modo inalterado con el paso de los siglos suponía que los historicistas no iban a reparar en ella. 
Ciertamente, en la esclavitud tenemos una buena muestra de lo que es un proceso de larga duración y cómo éste se apoya en una mentalidad que varía muy lentamente a lo largo de los siglos.

Por otra parte, y en lo que respecta a los reinos españoles, la esclavitud la vemos durante el período medieval muy ligada a la pugna cristiano-musulmana, y así los cristianos son esclavizados por los musulmanes y éstos por los cristianos. Y esta fue también una vía para la entrada de los negros como esclavos en España, puesto que ellos se contaban entre la población musulmana como fuerzas de choque militar o como esclavos en la sociedad civil. La asimilación de la condición de musulmán con la de esclavo en la España cristiana parece que era bastante general, pues según cuenta Braudel ${ }^{1}$, en 1539, en el Rosellón, se descubrió a un turco robando que no tenía amo alguno, por lo que se le prendió y luego fue vendido como esclavo. También la servidumbre como criados estaba próxima a la condición de los esclavos, y así, en las Cortes del año $1590^{2}$, se hizo la petición de que los criados no pudieran abandonar a sus señores sin licencia de éstos, libertad que los fueros municipales habían reconocido desde el siglo XIII, y sin la cual, ciertamente, lo que queda es la esclavitud. Posteriormente, y por la expansión castellana a las Indias, tenemos, por una parte, la pretensión colombina de esclavizar a los indios como forma de rentabilizar al máximo la explotación colonial, lo que no permitieron los Reyes Católicos, y poco después sería Bartolomé de las Casas el que, para librar a los indios de los trabajos a los que los sometían los encomenderos, recomendaría llevar esclavos desde África para que sustituyeran a los indios aborígenes en esas tareas. Planteamiento parecido es el que vemos en 1610, los franciscanos solicitaban una licencia de esclavos negros para venderlos y conseguir por esa vía fondos con los que rescatar esclavos blancos en tierras berberiscas $^{3}$, mientras el padre Las Casas quiere librar a los indios de los trabajos a que los someten los españoles y propone que los realicen esclavos negros, los franciscanos venden esclavos negros para liberar a esclavos blancos.

La expansión europea a América llevó consigo un crecimiento del tráfico negrero y del esclavismo para el desarrollo de cultivos, como el de la caña de azúcar, y otros trabajos, de modo que el esclavismo fue creciendo y extendiéndose como una mancha de aceite por el Nuevo Mundo, en un proceso que ha sido bastante estudiado, y parece que cuando se habla de esclavitud en los tiempos modernos solamente nos referimos a ese fenómeno en América y que es prácticamente inexistente en Europa, en general, y en España en particular. Del protagonismo de España en el tráfico negrero y el comercio de esclavos da buena idea el hecho de que el Código negro carolino, prontuario de instrucciones para dueños de esclavos, recopilado entre 1528 y 1768 por las autoridades españolas, fue el manual de uso

1 F. Braudel: El Mediterráneo y el mundo mediterráneo en tiempos de Felipe II. Madrid, 1980, Tomo II, p. 138.

2 R. GiBeRT: Historia general del Derecho español. Madrid, 1981, p. 211

3 A. M. Bernal: España, proyecto inacabado. Costes /beneficio del Imperio. Madrid, 2005, p. 451. 
de los esclavistas europeos en América, e incluso llegó a ser adoptado oficialmente por Francia en sus colonias de La Luisiana ${ }^{4}$.

Durante el siglo XVI, en Castilla, la presencia de esclavos se nos relata como muy escasa en la Meseta Norte, más nutrida en Madrid y, especialmente, en Sevilla, donde en un padrón eclesiástico del arzobispado hispalense realizado en $1565^{5}$ se cuentan hasta 14.670 esclavos, de ellos 5.327 en la propia ciudad, lo que representaba entre el 6 y el $7 \%$ de la población sevillana, estimando Domínguez Ortiz que en toda Andalucía podrían ser 30.000 los esclavos existentes, predominando los esclavos blancos ${ }^{6}$, con respecto a los negros. Sevilla fue en el siglo XVI un gran mercado de compraventa y reexportación de esclavos, operaciones que se realizaban a la luz del día en un lugar tan público como eran las gradas de la catedral.

Pero si la esclavitud estaba ligada en Indias a la explotación económica, en Castilla se presenta por algunos historiadores como algo exótico, como una muestra de riqueza de sus propietarios, y no se relaciona, en general, a los esclavos con trabajos concretos y si con que su actividad se realizaba en el ámbito doméstico de sus propietarios. Realmente, los esclavos formaban la minoría más intensamente marginada, hasta el punto de que las leyes civiles ni siquiera se ocupaban de ellos, era como si no existieran tales personas pues en los padrones vecindarios ni siquiera se mencionan, y de las que casi sus únicas noticias las tenemos a través de las disposiciones testamentarias de algunos propietarios de esclavos, que in articulo mortis les concedían la manumisión, dando lugar a la existencia de libertos, aunque con frecuencia esa libertad se les coartaba al establecer algunas limitaciones a favor de la familia del antiguo dueño; a este respecto hay una cita en el Quijote ${ }^{7}$ que es bien ilustrativa de cómo la manumisión de esclavos no era, en algunos casos, una muestra de humanización por parte de los propietarios, y dice así: «no es bien que se haga con ellos [los soldados viejos y estropeados] lo que suelen hacer los ahorran y dan libertad a sus negros cuando ya son viejos y no pueden servir, y echándolos de casa con título de libres, los hacen esclavos de el hambre, de quien no piensan ahorrarse sino con la muerte".

Ya hemos citado la contradictoria propuesta de Las Casas, que para evitar penalidades a los indios proponía fueran sustituidos por esclavos negros africanos, es decir, éstos si podían ser esclavizados mientras los indios y blancos se libraban de ese estigma, y esto era a principios del siglo XVI. La visión lascasiana no se des-

${ }^{4}$ A. M. Bernal: España,..., p. 230.

5 A. Domínguez OrTIZ: «Felipe II y las minorías marginadas», en F. Ruiz MARTín (coord.): La monarquía de Felipe II. Madrid, 2003, pp. 413-418.

${ }^{6}$ Los denominados esclavos blancos eran, en general, musulmanes, entre los que se contaron muchos moriscos granadinos tras la guerra de las Alpujarras, pues la reducción a la esclavitud de poblaciones enteras no fue infrecuente, aunque muchos de ellos recuperarían la libertad tras el pago de un rescate; también se dio el caso de moriscos que se ofrecieron a los castellanos como esclavos para no someterse a la expulsión en 1610.

7 M. DE Cervantes: Don Quijote. II parte, cap. XXIV. 
viaba mucho de la que se tenía en otros lugares del Viejo Continente, como nos relata Burckhardt ${ }^{8}$ en relación a los torneos que se celebraban en la corte papal de Alejandro VI, cuando en uno de estos sangrientos espectáculos el cardenal Ascanio Sforza le pregunto al príncipe turco Dschem qué le parecía lo que había visto, y éste le contestó que en su patria esos combates se celebraban con esclavos, para no lamentar la pérdida de la vida de los combatientes turcos si caían en el torneo. Y es que la esclavitud era aceptada por lo teólogos del siglo XVI, igual que por el resto de la sociedad, laica o eclesiástica, porque para todos servían de justificación las palabras de San Pablo a los colosenses: Esclavos, obedeced en todo a vuestros amos en este mundo [...] amos, dad a vuestros esclavos lo que es justo $y$ equitativo (Colosenses 3, vv. 22 y ss.); como consecuencia de esta aceptación del hecho esclavista por el cristianismo, uno de los grupos que aparecen entre los propietarios de esclavos era el de los eclesiásticos.

Si recorremos en la memoria el tiempo del Antiguo Régimen y nos fijamos en el proceso que se abrió tras su ruptura con la Revolución francesa, vemos en la Declaración de los Derechos del Hombre cómo se decía que: «todos los hombres nacen y permanecen libres e iguales en derecho», y también se precisaba que los derechos del hombre eran cuatro: la libertad, la propiedad, la seguridad y la resistencia a la opresión. Esta bella declaración podrá criticarse porque omitía una palabra, y es que realmente se debería haber titulado «de los derechos del hombre blanco», pues Francia, en aquellos años finales del siglo XVIII, tenía una próspera explotación esclavista en sus posesiones americanas, y ciertamente durante los debates se pensó en que esta declaración de los derechos del hombre suponía inexorablemente la abolición de la esclavitud en todos los territorios sometidos a la soberanía francesa, y así había diputados que calificaban a la esclavitud como atentado contra los derechos humanos, y otros, como Montesquieu, estimaban que la esclavitud era un freno para el desarrollo económico, pues en aquellas actividades que ejecutaban hombres libres se conseguían rendimientos superiores a los que producían los esclavos. Es decir, la esclavitud era rechazada por algunos diputados basándose en criterios jurídicos, otros lo hacían por razones de eficiencia económica, y también estaban los que pretendían mantener la esclavitud sin hacer mención alguna de ella, pues suprimirla habría sido una ruina para la economía francesa, y así en el debate se defendió que era preferible sacrificar a media millón de esclavos que a los 27 millones de franceses, y para ello había que dejar como intocable el derecho de propiedad sobre los esclavos, es decir, se estableció una prelación del derecho de propiedad sobre el de la libertad. ¿Y cómo se resolvió esta contradicción de proclamar a todos los hombres libres y, a la vez, mantener la esclavitud? Pues igual que habían hecho para extinguir la revuelta campesina de la Vendee, deshumanizando a los campesinos de esa región al considerarlos como bestias a las que había que dar caza hasta su total desaparición, también se consideró a los esclavos como cosas, en la tradición romana para la que el esclavo era

8 J. BuRCKHARDT: La cultura del Renacimiento en Italia. Madrid, 2004, p. 313. 
una cosa con voz. No obstante, la Convención, en 1794, aprobó la abolición de la esclavitud, pero muy poco después, en 1810, Napoleón Bonaparte la volvió a legalizar.

La visión deshumanizada de los esclavos también formaba parte de la mentalidad de los castellanos, y así podemos leer en Guzmán de Alfarache ${ }^{9:} Y$ para nunca perderla en cuanto yo alli estuviese y mejor poder obligarla, ibala sustentando con palabras y esperanzas que teniendo con qué buscaría como ahorrarla [liberarla de la esclavitud] y me casaría con ella. Esto le hacía desvelar y enloquecer en mi servicio. Porque el amor que le fingí, aunque muy astuta, siempre lo tuvo por cierto, como si yo no fuese hombre y ella esclava, es decir, la esclava no formaba parte de la humanidad.

En los propios contratos de compraventa o tráfico negrero, no se cuentan los esclavos como personas sino como «piezas», es decir, se establecía como unidad a un esclavo joven, fuerte y sano, y en relación a éste módulo los demás eran, según su sexo, edad, salud y constitución física, una fracción de esa pieza, y de tal modo, un contrato de 1.000 piezas podía afectar a casi 1.500 personas; así, en un contrato con el armador Francisco Solórzano para un viaje a Berbería en 1549, se decía: «[...] aveis de ser obligado [...] de me dar e pagar por cada pieça de esclavos negros que resgataredes por mi industria e solicitud, e de todas las demás que en qualquier manera ovieredes en Berbería [...] a seis reales de plata viejos, eceto de las criaturas que mamaren, que destas no aveis de pagar cosa alguna [...]; e otro si, es condición que todas las piezas, negros o negras, que yo oviere en Berbería [...] » ${ }^{10}$; esta misma expresión se trasladó a América y se decía «pieza de Indias» para referirse a la unidad objeto del comercio esclavista, y ello se recogió también en los acuerdos internacionales, pues en el Tratado del asiento de negros, formalizado entre España e Inglaterra en 1713, se le concedía a ésta el derecho a introducir en los puertos de las Indias hasta 144.000 piezas de Indias, lo que realmente podría afectar a unas 200.000 personas.

Otros elementos que contribuían a diluir la realidad de la población esclava en la sociedad española del siglo XVI era que los contaban dentro del grupo de los ilegítimos, e incluso en los vecindarios concejiles no se hace ninguna mención de ellos, dejando en la duda al investigador si cuando se cuentan los criados están incluidos también los esclavos; solamente en las actas sacramentales se distingue ciertamente entre una u otra condición. Esta marginación de los esclavos la vemos igualmente reflejada en una tan alta instancia como era la persona de Carlos I, quién en las instrucciones que en 1548 daba a su hijo Felipe, le decía que no dejara de atender en su gobierno el cuidado de pobres, desamparados, huérfanos y viudas.

${ }^{9}$ M. Alemán: Guzmán de Alfarache. Parte II, Libro III, Cap. VII.

10 J. L. CoRTÉs López: La esclavitud en España en la época de Carlos I. Biblioteca virtual Cervantes/historia/Carlos V, p. 6. 


\section{LA ESCLAVITUD EN EXTREMADURA}

Como antecedentes relativos a la esclavitud en Extremadura para esta centuria que estudiamos, Rodríguez Blanco ${ }^{11}$, en su obra sobre la Orden de Santiago, trata de los esclavos englobándolos dentro del grupo de los marginados y dice que aparecen incluidos en las posesiones de los comendadores como si formaran parte de sus bienes muebles, y que nunca son enumerados, ni se reseña el sexo, edad, procedencia o cualquier otro detalle que los pudiera caracterizar como un grupo humano. Francisco Zarandieta ${ }^{12}$, en su investigación sobre la población de Almendralejo, establece una tipología de la pobreza, según un vecindario de 1586, distinguiendo entre pobres y no pobres según los sexos; en los varones se registran varones con oficio, sin oficio y moriscos, y entre las mujeres se anotan viuda, con marido ausente, libertas, mulatas, beatas y solteras; como vemos, en el grupo femenino se recuerda la condición esclava que tuvieron las libertas, y quizás las mulatas; pero ni en uno ni en otro grupo aparecen esclavos, como si no fueran personas a contar.

También los tribunales de la Inquisición, en las actas de sus procesos, detallan la condición esclava de algunos de sus acusados ${ }^{13}$, en Llerena, entre 1575 y 1596, se procesaron a 357 personas por el delito de fornicación, de las cuales el $85 \%$ eran hombres y el resto mujeres; los varones eran mayoritariamente solteros mientras que las mujeres estaban casadas o lo habían estado, el $97 \%$ de los procesados eran extremeños y el resto portugueses, 15 de los procesados eran moriscos y 7 , varones, esclavos; este dato nos hace ver que, en este grupo, los esclavos representaban el 1'96\%.

Entre los años 1581 y 1585 los obispos realizaron en sus respectivas diócesis un recuento de los moriscos asentados en ellas, y tales relaciones fueron recogidas por Tomas López en su censo de la Corona de Castilla del año $1591^{14}$, en las que se reseñan los siguientes datos sobre los moriscos en las diócesis extremeñas, sin que aparezcan los correspondientes a los ubicados en territorios de Ordenes Militares, de tanta extensión en Extremadura:

- Obispado de Badajoz

- Varones libres mayores de 10 años ........................478 478

- Mujeres libres mayores de 10 años ....................... 498

- Niños menores de 10 años .....................................295

- Esclavos y esclavas ............................................213

11 D. Rodríguez BLanco: La Orden de Santiago en Extremadura (siglos XIV y XV). Badajoz, 1985, p. 383.

12 F. Zarandieta Arenas: Almendralejo en los siglos XVI y XVII, Almendralejo, 1993, p. 73 (los datos proceden del AGS: EH, leg. 38-8-1).

${ }^{13}$ M. ${ }^{a}$ A. HeRnándeZ e I. M. ${ }^{a}$ TeSTÓN: "Sexualidad e Inquisición en Llerena». Revista de Estudios Extremeños. Tom XLIX, Num. III, (1988), pp. 623-660, la referencia en p. 658 (nota 49).

${ }^{14}$ Las relaciones episcopales se encuentran en el Archivo General de Simancas: Gracia y justicia. Estado de Castilla. Mazo 2196. Con estas referencias aparecen en «Censo de población de las provincias y partidos de la Corona de Castilla en el siglo XVI.». Madrid, Imprenta Real, 1829, p. 363. 
- Obispado de Coria

- Varones libres mayores de 10 años .......................267

- Mujeres libres mayores de 10 años ........................282

- Niños menores de 10 años ...................................204

- Esclavos y esclavas .............................................265

- Obispado de Plasencia

- Hombres mayores de 18 años 439

- Mujeres mayores de 15 años 423

- Niños menores de 15 años 575

- Viejos mayores de 50 años 102

- Viejas mayores de 50 años 85

- Esclavos 3

Es evidente la importancia que representa la esclavitud de moriscos en las diócesis de Badajoz y Coria, pero es difícil valorarla debidamente pues desconocemos cual era su distribución entre los diversos lugares que componían la población del territorio diocesano. Posiblemente, por el hecho de que esta población morisca, en gran parte, había sido trasladada recientemente desde las tierras de Granada, habría facilitado el hecho de incrementar el esclavismo en las tierras de sus nuevos asentamientos, pero fuese así, o no, el hecho cierto es que la población esclava existía.

Como ya se ha indicado, los protocolos notariales son una importante fuente de información para conocer la esclavitud, y a ese campo ha dedicado un trabajo $\mathrm{Pe}$ ríañez Gómez ${ }^{15}$, centrado en los años de 1577 a 1599 para la localidad de Llerena, donde se ubicaba un mercado de esclavos, aunque en su opinión el mercado esclavista de Zafra ofrecía una mayor variedad de «piezas» y a precios más competitivos que en Llerena; en su estudio ha analizado 222 documentos con referencia a la esclavitud (escrituras de compraventa, inventarios, cartas de dote, poderes para la captura de eslavos, cartas de horro, etc.), y hace notar la presencia de portugueses como agentes en muchas de esas transacciones, como vemos en 1588 cuando, en Zafra ${ }^{16}$, Hernando Machado compra al portugués Álvaro Gonçalez, una esclava llamada Dominga, de 25 años, junto con una hija de 4, por cuya compra pagó 135 ducados; este mismo propietario, en 1591, adquirió a otro de Almendralejo, un esclavo de 28 años por el que pagó 120 ducados ${ }^{17}$. Como datos cuantitativos, Periáñez nos da el total de esclavos objetos de comercio en ese espacio temporal, que fueron 127 (64 hombres y 63 mujeres); el $65 \%$ de los esclavos vendidos en Llerena tenían edades comprendidas entre 15 y 35 años; el precio medio de un esclavo era de $78^{\prime} 7$ ducados, pero por los jóvenes, con edades

15 R. PeríAÑez GómeZ: «Aproximación a la esclavitud en Llerena en el siglo XVI». Actas de las III Jornadas de Historia de Llerena, Llerena, 2002, pp. 129-139.

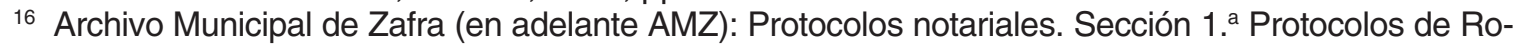
drigo de Paz. 1588 (1), fs.322-323

17 A.M.Z.: Protocolos notariales. Sección 1. ${ }^{a}$ Protocolos de Rodrigo de Paz (1590-91), fs. 684-685. 
entre 18 y 24 años, se llegaba a pagar una media de 101'3 ducados, mientras que por los niños menores de 10 años, y por los adultos mayores de 40 años, sólo se alcanzaban los 38 ducados como precio medio, debiéndose consignar que entre ellos predominaban los esclavos de raza negra.

La actitud de los propietarios respecto a sus esclavos variaba entre los que únicamente los consideraban como objetos productivos o vendibles y la de aquellos que mantenían unas relaciones de convivencia amistosa, lo que se manifestaba especialmente en el momento de la muerte de los propietarios que en su testamento les dejaban legados significativos e, incluso, le concedían la carta de ahorría para que fueran libres en lo sucesivo. En Mérida, Guiomar, una esclava de Francisco Zimbrón y Saavedra, cuando murió en 1623 tuvo un entierro de capas y en sepultura propia.

Pero esta liberación de los esclavos proclamada en los testamentos muchas veces no era plena, como vemos en el testamento del licenciado Cristóbal Fernández ${ }^{18}$, presbítero de la Zarza, quien declara poseer: «[...] a María Hernández y a Juan su hijo, y Catalina, mis esclavos, quiero y es mi voluntad por obra para darles, como les doy, libertad después de mis días, y que lo sean libres con calidad que el dicho Juan aya de estar y esté a la orden que le dirá el licenciado Bernardino Barrero [presbítero vecino de la villa de La Oliva] y tenga obligación de hacer lo que le ordenare como patrón suyo, y no lo haciendo lo castigue y haga castigar [...] Digo que tiene dado dendina de año y medio a María su esclava, hija de María Hernández su esclava, que al presente la dicha María será de hedad de catorce años poco más o menos, a doña María su sobrina, la que la ha criado y alimentado y ha tenido y tiene en su poder, quiere y es su voluntad la aya para siempre xamas para su servicio, porque desde luego se lo manda y da y hace donación [...]".

La posesión de esclavos por los clérigos esta muy generalizada, y de ello es un buen testimonio el que ofrece Cortés López ${ }^{19}$ sobre el monasterio de Guadalupe, donde, según el texto de una visita en 1542, se dice: «todos estos oficiales y servidores [...] van a comer a un refectorio, junto al cual tienen su cocina y despensa, donde hay mesas separadas con títulos en las paredes que declaran cuya mesa es, en el que también los esclavos tienen la suya»; pero no sólo el monasterio se servía de los esclavos sino que también comerciaba con ellos, como se atestigua por el cardenal de Burgos, fray Juan de Toledo, el cual da fe en Roma, que el Papa Julio III, por un breve fechado en marzo de 1550, mantenía todos los privilegios y gracias que había concedido al monasterio, y entre esas concesiones estaba la venta libre de los esclavos pertenecientes al convento: «Item. El cardenal de Sant Angel, Penitenciario del Papa Julio III y de su especial mandato, concede a este monasterio de Guadalupe que el Prior que es o fuere con su convento, pueda ven-

18 Documento formalizado ante el escribano público Juan Cortés Lorano, sobre papel del sello primero, de 272 maravedíes, del año 1637, con el escudo de Felipe IV.

19 J. L. CORTÉs López: La esclavitud ..., p. 19. 
der y enagenar cualesquier esclavos inútiles y superfluos para el servicio desta casa, ora los ofrezcan, ora los donen para que sirvan en ella, y que el precio dellos se eche en las cosas más necesarias para el monasterio, y con esto se cumple con la voluntad de quién los ofreció o dio [...]", texto que nos informa también de cómo el monasterio recibía esclavos por donaciones que hacían sus benefactores.

Zarandieta, en su historia de Almendralejo ${ }^{20}$, ofrece un amplio epígrafe dedicado a la esclavitud en aquella villa, atestiguando que esa forma de segregación social era habitual para los extremeños de aquellas centurias, siendo la captura en las guerras contra infieles la causa más extendida para el acceso a la esclavitud, lo que testimonian los documentos con la expresión avido en buena guerra, y a los cuales se les considera como unos bienes materiales por sus propietarios, y así son incluidos en las relaciones de bienes inventariados, en las transmisiones hereditarias y en las escrituras de partición y de donación. Con relación al mercado esclavista, Zarandieta cuenta hasta 72 piezas compradas (17 hombres y 55 mujeres); los varones tenían edades comprendidas entre 25 y 34 años, mientras que las de las mujeres oscilaban entre 10 y 29 años. Respecto a la tipología racial de los esclavos nos proporciona una detallada relación de colores que los caracterizaba en la pigmentación de su piel, que fueron reseñados en la documentación de sus contratos de compraventa, y que señalan como tipos diferenciados los siguientes: mulato, negro, blanco, mulato blanco, negra tinta, negro atezado, mulata baza, tinto, moreno atezado, negra no muy tinta, negra tinta atezada, mulato amembrillado, mulato amembrillado indio, negro bazo, blanco mulato, mulato amembrillado oscuro, mulato bazo amembrillado, amembrillado bazo, tinta atezada, amembrillado oscuro, tinta oscura, amembrillado que dice a blanco, bazo amembrillado, blanco amarillo, mulata amembrillada cocho, blanco rubio, tinto bazo oscuro, cocho, pardo membrillo cocho, moreno, tinto algo bazo, bazo pardo, bazo que tira a claro, morena que dice a blanco, bazo oscuro, retinto, mulato claro y blanca quebrada de color amembrillado. Además de estas características raciales, que dan testimonio cierto de un intenso y extenso proceso de mestizaje, también se reseñan algunas características físicas o morales, como «sano y no posee mal corazón, gota, coral ni perlesía», «no está endemoniado ni padece bubas ni ninguna otra enfermedad pública ni privada, ni tiene otra falta, ni está sujeta ni hipotecada a ninguna deuda ni delito», «no es loco, endemoniado, ladrón, borracho ni fugitivo», «no está casado», «está embarazada», «buena presencia», «buena cara», «buena persona».

Se podrían exponer más testimonios de otros lugares de Extremadura donde aparecen esclavos, sabiendo además que en general están diluidos dentro de otros grupos o, simplemente, no se reseñan porque no se cuentan como personas, y así, en las visitas de la Orden de Santiago a sus encomiendas, que tan prolijas son en muchas cuestiones, ignoran por completo a este grupo social. Por ello, para

20 F. Zarandieta AREnAS: Almendralejo ..., t. I, pp. 334 a 366. (La mayor parte de este texto corresponde a datos del siglo XVII, por lo que solamente recogeremos en este artículo los del siglo XVI, aparte de las informaciones de carácter general). 
conocer en alguna medida cuanto representaban en los vecindarios de los lugares, haremos una aproximación cuantitativa con los datos disponibles.

\section{UNA APROXIMACIÓN CUANTITATIVA A LA ESCLAVITUD EN EXTREMADURA}

Aunque hay diversidad de trabajos en los que aparece el tema de la esclavitud, son sin embargo pocos los que proporcionan datos cuantitativos que nos permitan conocer el peso que ese grupo social tenían en las poblaciones estudiadas. Uno de los que proporcionan una mayor riqueza de datos es el de Fernando Cortés para Badajoz $^{21}$, que aunque sobrepasa el ámbito temporal sobre el que centramos nuestro estudio, el correspondiente al siglo XVI, no obstante tomaremos sus datos comprensivos de la natalidad entre los años 1550 y 1699, que ciertamente no podemos presentar como representativos del conjunto del reino castellano, pues durante la segunda mitad del siglo XVII el azote apocalíptico de la guerra con Portugal fue mucho más lacerante en Badajoz que en ninguna otra parte; pero también esta situación tuvo bastante incidencia en el micromundo de la esclavitud.

Durante esos años se bautizaron en Badajoz 51.435 personas, de las cuales 655 eran de condición esclava, lo que representa que el 1'2\% de los bautismos eran aplicados a esclavos. El desglose según los progenitores de éstos es el siguiente:

Bautismo de esclavos en Badajoz 1550-1699

\begin{tabular}{|c|c|}
\hline Progenitores & Número de hijos \\
\hline - Padre conocido y madre esclava & $7(1$ '07\%) \\
- Padre desconocido y madre esclava & $646(98$ '62\%) \\
- Padre esclavo y madre conocida & $2\left(0^{\prime} 31 \%\right)$ \\
\hline
\end{tabular}

Como vemos en la tabla anterior, es absolutamente mayoritaria la filiación generada por padre desconocido y madre esclava, y la variación dentro de este grupo entre un siglo y otro es la siguiente

Bautismos en Badajoz desglosados por siglos

\begin{tabular}{|c|c|c|}
\hline \multicolumn{1}{|c|}{ Bautizados } & Siglo XVI & Siglo XVII \\
\hline $\begin{array}{l}\text { - Bautizados en total } \\
\text { - Hijos de padre desconocido } \\
\text { y madre esclava }\end{array}$ & 18.750 & 32.685 \\
\hline
\end{tabular}

21 F. CoRTÉs CoRTÉs: Una ciudad de frontera. Badajoz en los siglos XVI y XVII. Badajoz, 1990, pp. 165-178. 
Estos datos muestran una disminución notable en el nacimiento de esclavos, que no tiene correlación con el conjunto de nacidos ilegítimos dentro del mismo período, que representa el $10 \%$ de los bautizados durante el siglo xvI y el 10 ' $52 \%$ durante el siglo XVII. Cortés da una explicación acerca de esta disminución del número de bautismos de esclavos argumentando que, por una parte, el esclavo es un bien económico para los propietarios y que éstos, en épocas de dificultades financieras encuentran un alivio en la venta de sus esclavos; de otro lado, el propio hecho de la guerra y la consiguiente movilidad de grupos humanos en torno a la frontera favorecía la huida de esclavos adultos a Portugal, posiblemente buscando en este país la pérdida de su condición social y la consecución de la libertad; recíprocamente también había esclavos portugueses que se introducían en Castilla por las mismas motivaciones.

Del mismo autor, Fernando Cortés, tenemos un artículo sobre esclavos en la villa de Montijo ${ }^{22}$, en el cual estudia los bautismos registrados entre 1594 y 1665 , donde se reseñan 39 esclavos, y aunque no llega a conocer el volumen de esclavos existentes en esa localidad, sí detecta que en el siglo XVI fueron más numerosos que en el XVII, y entre otras informaciones señala que las esclavas eran poseídas, en muchos casos, para ser nodrizas de los hijos de sus dueños, circunstancia que requería el que se quedaran preñadas con algunos meses de antelación a sus respectivas propietarias para que cuando naciera el hijo de éstas ellas les pudieran proporcionar la lactancia desde el mismo momento de su nacimiento. El amancebamiento con esclavas fue una cuestión tratada en el Sínodo diocesano de Badajoz del año 1671, que promulgó la disposición siguiente: Pónense especialmente penas contra los amancebados con sus esclavas; porque ha llegado la malicia a tanto que, pospuesto el temor de Dios y en gran cargo de sus ánimos y conciencias, unos las compran para usar mal de ellas y otros las consienten amancebadas por los intereses de los hijos que les parieren, es decir, las esclavas interesaban como amas de cría y como productoras de esclavos.

También Fernando Cortés nos da noticias, aunque sin cuantificar, sobre la esclavitud en la villa de Zafra ${ }^{23}$, que tenía una considerable importancia numérica, cuya evolución muestra un claro predominio en las décadas centrales del siglo XVI y notable reducción en las décadas finales de esta centuria y la primera mitad de la siguiente, manifestándose una recuperación en la segunda mitad. Sí detalla que los propietarios de esclavos eran altos funcionarios y clérigos y que la población esclava era negra.

Para la villa de Almendralejo tenemos la información que proporciona Zarandieta $^{24}$, que a partir de los registros de bautismo en la parroquia consigue los siguientes datos:

22 F. Cortés Cortés: «Los esclavos en Montijo», Alminar, n. ${ }^{\circ}$ 15, (1980), pp. 4-6.

${ }^{23}$ F. CORTÉs CORTÉS: «La población de Zafra en los siglo XVI y XVII», Revista de Estudios Extremeños, Tomo XXXVI, n. III, (1985), pp. 525-532.

${ }^{24}$ F. Zarandieta Arenas: Almendralejo ..., t. I, pp. 320-342. 
Esclavos bautizados en Almendralejo (1571-1600)

\begin{tabular}{|c|c|c|c|c|c|}
\hline \multirow{2}{*}{ Años } & \multicolumn{3}{|c|}{ Esclavos bautizados } & \multirow{2}{*}{$\begin{array}{c}\text { Bautismos } \\
\text { totales }\end{array}$} & \multirow{2}{*}{$\%$ esclavos } \\
\hline & Varones & Mujeres & Total & & \\
\hline $1571-1580$ & 38 & 32 & 70 & 1.440 & 4'9\% \\
\hline $1581-1590$ & 18 & 14 & 32 & 1.327 & $2 ' 4 \%$ \\
\hline $1591-1600$ & 17 & 17 & 34 & 1.249 & $27 \%$ \\
\hline
\end{tabular}

Es evidente el descenso del crecimiento de la población por la vía de los nacimientos, y si asignamos el valor 100 a los valores de la década 1571-1580, tendremos para la siguiente que el índice de bautismos de esclavos es de 45'5, y para la década siguiente, y última de las consignadas en la tabla, es 48'6; igualmente para los bautismos totales los índices serían 92 '2 y 86'7 respectivamente. Como valor medio de las tres décadas registradas, los esclavos han supuesto el 3'39\% de los bautismos totales; también señala que en un censo del año 1589 se registran 6 esclavos moriscos. Para el conjunto de los registros efectuados por Zarandieta, que cubren hasta el año 1700, se reseñan los bautismos de 15.259 personas, siendo 652 de condición esclava, es decir, el 4'3\%; también muestra que en una Matricula del año 1665 relativa a los habitantes en edad de comulgar, es decir, los mayores de doce años, aparecen citados 63 esclavos, lo que representaría el 5 '5\% de la población, y en el Vecindario se reseñan 105 esclavos, los cuales aportaban el 6'3\% de la población.

Dentro de la Baja Extremadura, y próxima a Almendralejo, está la localidad de La Fuente del Maestre, sobre la que hay un estudio demográfico realizado por Antonio Carretero ${ }^{25}$, del que tomamos los datos de bautismos totales y de esclavos realizados durante el siglo XVI.

Esclavos bautizados en La Fuente del Maestre (1555-1601)

\begin{tabular}{|c|c|c|c|c|}
\hline Período & N.o de años & Esclavos & $\begin{array}{c}\text { Bautismos } \\
\text { totales }\end{array}$ & $\begin{array}{c}\% \text { esclavos } \\
\text { bautizados }\end{array}$ \\
\hline $1555-1561$ & 7 & 26 & 668 & $4^{\prime} 19 \%$ \\
$1562-1571$ & 10 & 28 & 1.131 & $2 ' 48 \%$ \\
$1572-1581$ & 10 & 28 & 1.402 & $2{ }^{\prime} 00 \%$ \\
$1582-1591$ & 10 & 53 & 1.587 & $3{ }^{\prime} 34 \%$ \\
$1592-1601$ & 10 & 34 & 1.368 & $2 ' 41 \%$ \\
\hline $1555-1601$ & 47 & 169 & 6.156 & $2 ' 74 \%$ \\
\hline
\end{tabular}

25 A. Carretero Melo: «Fuente del Maestre en la Edad Moderna. Sociedad». Proserpina, n. ${ }^{\circ}$ 15, (2001), pp. 77-119. 
Como el primer rango temporal conocido, 1555-1601, es menor que los siguientes, para hacer una comparación precisa haremos una nueva tabla tomando como valores las medias de bautismos en cada período, y es la siguiente:

\begin{tabular}{|c|c|c|c|}
\hline Período & Bautismos totales & Bautismo de esclavos & Porcentaje esclavo \\
\hline $1555-1601$ & $95^{\prime} 43$ & $3^{\prime} 71$ & $3{ }^{\prime} 89 \%$ \\
$1562-1571$ & $113^{\prime} 1$ & $2 ' 8$ & $2 ' 48 \%$ \\
$1572-1581$ & $140^{\prime} 2$ & $2 ' 8$ & $2 ' 00 \%$ \\
$1582-1591$ & $158^{\prime} 7$ & $5^{\prime} 5$ & $3{ }^{\prime} 34 \%$ \\
$1592-1601$ & $136 ' 8$ & $3^{\prime} 4$ & $2 ' 49 \%$ \\
\hline
\end{tabular}

A simple vista se observa que las cifras de bautismos no se mueven con la misma intensidad, y ello se corrobora al determinar el índice de correlación entre la serie de bautizados totales y de bautizados esclavos, que nos da un valor de 0'48. Para conocer la evolución de ese proceso demográfico con mayor detalle, convertiremos los valores de la tabla anterior a números índice, y sobre éstos estableceremos las líneas de tendencia de cada serie, lo que exponemos conjuntamente en un gráfico, donde se aprecia cómo las tendencias son crecientes y positivas, pero con menor coeficiente en los esclavos; también se observa cómo en la década de 1581-90 se producen los valores máximos anuales de ambas series.

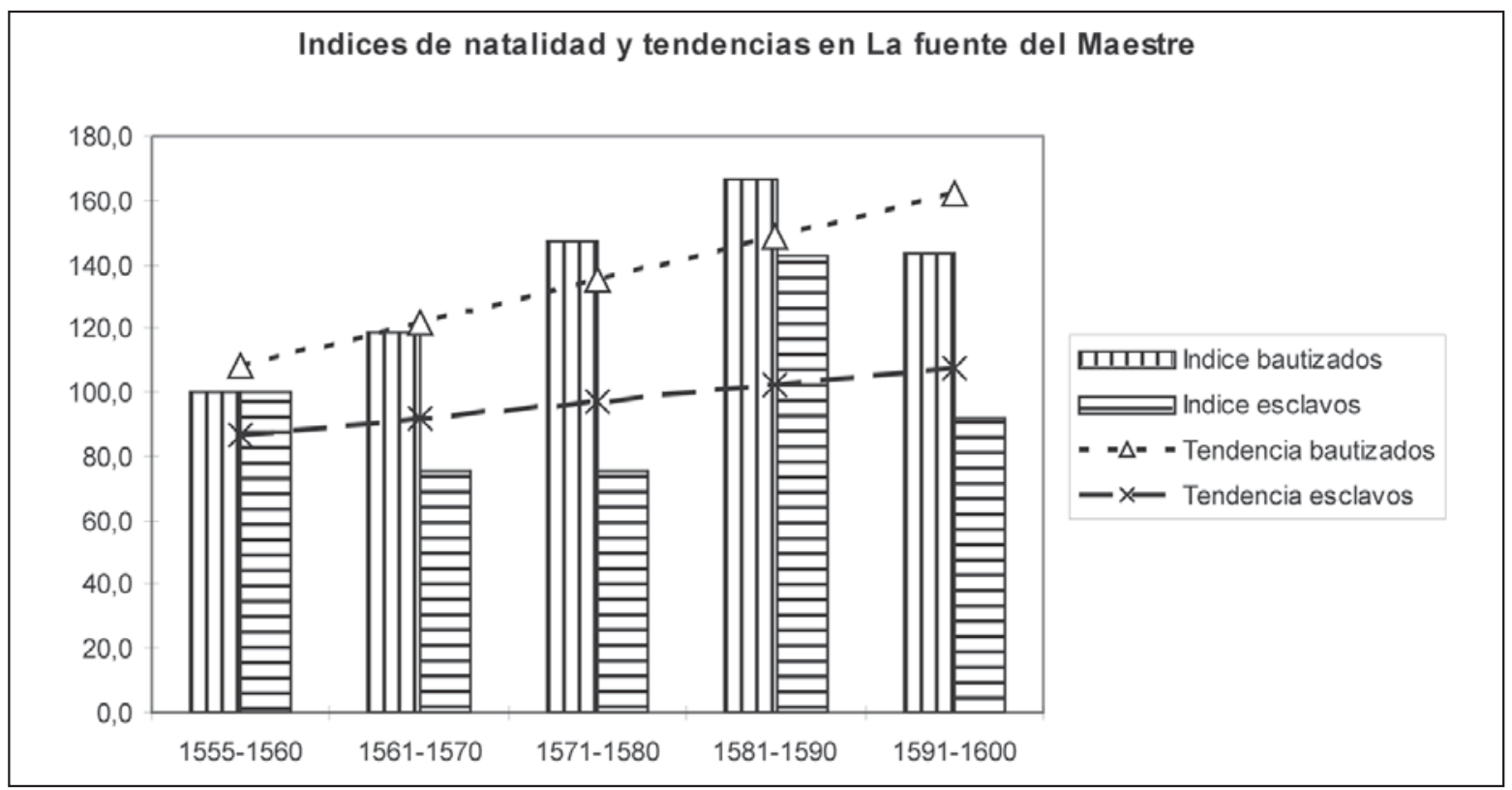

La media de esclavos bautizados en La Fuente del Maestre, expresada en porcentaje, es de 2'94\% a lo largo de todo el período de 1555 a 1601.

Otra población de la Baja Extremadura de la que hemos podido conocer algunos datos relativos a la esclavitud es Llerena, a partir de un Acta de Confirmación 
Sacramental, del 13 de junio de $1571^{26}$, en la que son relacionadas 262 personas, entre las cuales se contaban 11 esclavas y 9 esclavos, es decir, el 7'63\% de los confirmados, como vemos un porcentaje bastante más alto que el que nos han ofrecido las localidades anteriormente estudiadas. Estos 20 esclavos pertenecían a 14 propietarios, lo que nos da una relación esclavo/propietario de 1'43. Como información para la historia social, relacionamos los propietarios con los esclavos que presentaron para la Confirmación.

Esclavos confirmados en Llerena en 1571

\begin{tabular}{|l|l|}
\hline \multicolumn{1}{|c|}{ Propietarios } & Esclavos \\
\hline Pedro de Ordiales (Clérigo) & María \\
Luis de Cazalla & Catalina \\
Gonzalo de Mena & Sebastián \\
Isabel de Mena & María \\
& Isabel \\
Pedro Sánchez (Procurador) & Pedro \\
Catalina Mexía & Andrés \\
& Juana \\
Francisco Pizarro & Lorenza \\
& Gracia \\
Lope de Llerena & Juan \\
Rodrigo Garçon & Francisca \\
Hernán López Ortiz & Diego \\
Francisco Muñoz & Isabel \\
& Pedro \\
Barrial & Elena \\
Juan Fernández Montemayor & Diego \\
Leonor Álvarez & María \\
& Francisco \\
& Juan \\
\hline
\end{tabular}

Ángel Rodríguez Sánchez ${ }^{27}$ estudió la natalidad ilegitima en la villa de Cáceres durante el siglo XVI, y sobre un total de 8.624 bautizados detalla que 94 eran hijos de padre desconocido y madre esclava, y 1 era hijo de padre esclavo y madre desconocida; estas 95 personas representaban el 29'4\% del conjunto de los ilegítimos; pero analizando las relaciones nominales que expone en el Apéndice, aparecen 138 esclavos, es decir, el 1'6\% sobre el total de bautizados.

${ }^{26}$ Libro $1 .{ }^{\circ}$ de bautismo de las iglesias de Santiago y Nuestra Señora de la Granada, fs. 32 y $62 \mathrm{v}$, respectivamente (en las relaciones aparecen algunas duplicidades que han sido corregidas por nosotros). Estas actas han sido publicadas por L. J. GARRAIN VILLA: "Documentos sobre fray Luis Zapata de Cárdenas y otros evangelizadores llerenenses en los archivos de Llerena», en Fr. SEBASTIÁN GARCIA, (ed.): Extremadura en la evangelización del Nuevo Mundo. Madrid, 1990, pp. 393-199.

27 A. RodríGuez Sánchez: «La natalidad ilegitima en Cáceres en el siglo XVI». Revista de Estudios Extremeños, T. XXXV, n. ${ }^{\circ}$ I, (1979), pp. 123-164. 
Ángel Rodríguez explica en su estudio cómo había detectado que ciertas esclavas manifestaban un comportamiento reproductor regular, lo que le llevó a pensar que ello se debería a una planificación inducida por el propietario que hacía uso de la esclava biológicamente para la obtención de nuevos esclavos, lo que sería una fuente de renta, o quizá fuera un aprovechamiento similar al que antes hemos reseñado de los esclavos de Montijo según el estudio de Fernando Cortés. También comprueba Ángel Rodríguez, al comparar las distintas parroquias cacereñas, que en aquellas cuya feligresía contaba con una mayor población de condición nobiliaria, eran también donde se presentaba una mayor concentración de esclavos; mientras que las parroquias con población predominantemente pechera tenían menos esclavos, y como dato aporta que, entre los años 1560 y 1599, las feligresías con predominio de hidalgos registraron 80 esclavos, frente a los 43 de las parroquias de pecheros.

Agrupando los esclavos con sus propietarios, a partir de los datos del Apéndice que expone Ángel Rodríguez, hemos determinado que había 99 propietarios de esclavos en Cáceres, los cuales son citados en los bautismos de 138 esclavos. De las esclavas que han sido madres de los bautizados, en muchos casos, ni se registra su nombre, solamente su condición social, y en algunos registros en los que consta su identificación se dice que son criadas, en lugar de esclavas, pero de su hijo si se expresa que es esclavo; en otros casos, se registra la madre como criada en un nacimiento y como esclava en otro, era el caso de María Morena, propiedad de Villalobos Carvajal, que tiene un hijo, Andrés, en 1568, y otro, Juana, en 1569, es evidente que la madre es la misma persona y así la hemos considerado como esclava para ambos registros. Al hacer la agrupación de bautizados con sus propietarios y con sus madres, hemos comprendido a todos dentro del grupo de esclavos, lo que ha supuesto que pasemos de la cifra de 95 a 138 esclavos como censo efectivo; en algunas ocasiones, además de registrar su condición social, se añadía que era negra, y también es esta cualidad racial la que en algunos registros es empleada como identificativa de la madre; en total se puede estimar en $108 \mathrm{el}$ número de madres esclavas.

La madre esclava con más hijos se llamaba Isabel, su propietaria era Catalina Cortés; la relación de hijos y fechas de bautismos es la siguiente: Isabel (octubre de 1577), Manuel (noviembre de 1580), Ambrosio (agosto de 1582) y Diego, del que se dice «moro» (octubre de 1584). Parece ser que produjo un parto triple, porque en Noviembre de 1564 se bautizan María, Victoria e Isabel, hijas de una esclava de Diego de Carvajal.

La relación de propietarios de esclavos en Cáceres, es la siguiente: Alonso de Figueroa, Alonso de Ulloa Aldana, Alonso Espadero, Alonso Perero, Alonso Pizarro, Alonso Sánchez, Ana de Montalvo, Ana Muñoz, Antonio Gutiérrez Sanabria, Baltasar Jiménez, Bernáldez (Doctor), Carvajal y Teresa de Torres, Catalina Cortés, Cristóbal de Ovando, Don Gonzalo, Diego Amigo, Diego Cano Rocha, Diego de Carvajal, Diego de Castañeda, Diego de la Rocha, Diego de Pantoja, Diego de Pa- 
redes, Diego de Ulloa, Diego de Vargas, Diego Enríquez, Diego Pérez de Herrera, Diego Rocha, Diego Rosado, Espadero (licenciado), Esteban González, Fernando de Ulloa, Francisca Borjes, Francisca Picón, Francisco Calderón (Corregidor, en 1556), Francisco de Aldana, Francisco de Ávila, Francisco García Macotela, Francisco Téllez, García Gonçalez, García Holguín, Hernán Jiménez, Hernando Álvarez de Toledo, Hernando de Aldana, Hernando de Ovando (Comendador), Hernando de Ribera, Hernando de Sande, Isabel Becerra, Isabel de Torres, Isabel de Ulloa, Isabel Vaez, Jerónimo de Saavedra, Juan Bravo, Juan de Carvajal, Juan de Perero, Juan de Toledo, Juan de Ulloa Paredes, Juan de Vega, Juan Jiménez, Juan Martín Delgado, Juan Moreno Pozo, Juan Picón, Juan Pizarro, Juana de Ovando, Leonor de Saavedra, La lanza (Tendera), Lezcano, Lope Lorenzo (Albardero), Lorenzo de Ulloa Porcallo, Lorenzo Velasco, Luis de Cáceres, María Gómez, Martín de Lezcano (Licenciado), María Reinoso y licenciado Valverde, Melchor de Ulloa, Mencía de Sotomayor, Mercader, Monasterio de San Pablo, Ojalvo (Bachiller), Ovando, Pedro Cano, Pedro de Ovando, Pedro García de la Cámara, Pedro Pérez (Escribano), Pedro Rol de la Cerda, Portocarrero, Romero (Bachiller), Rodrigo de Chaves, Rodrigo de Ovando, Salinas (Licenciado), Sancho de Figueroa, Sancho de Paredes Golfín, Sancho de Perero, Valdés (Licenciado) y Villalobos Carvajal.

El mayor número de bautizados correspondió a Diego de Paredes, que presentó hijos de tres esclavas distintas entre febrero de 1561 y diciembre de 1569. Llama la atención que no se consigna en ningún caso que el propietario sea clérigo, salvo el Monasterio de San Pablo, mientras que si se señalan oficios políticos o grados universitarios.

Para la esclavitud en Mérida disponemos de los datos que proporcionan los archivos parroquiales ${ }^{28}$ en sus libros de bautismo, confirmaciones y matrimonios, cuyo estudio realizamos por el procedimiento de la agrupación por familias. Para la primera mitad de la centuria, los datos correspondían a los años de 1526 a 1539 , los cuales, además, no reseñan tanta información como los que se producen durante la segunda mitad, y solamente nos informan de la condición de esclava en el caso del bautismo de una adulta, Isabel, el 21 de mayo de 1534, de madre esclava, sin reseñar su nombre, y padre desconocido, solamente se reseña que su propietario era Rodrigo Díaz, y el 9 de marzo de 1534 se bautiza Beatriz, esclava de Francisco Picón, de la que no se registran los nombres de sus padres ni tampoco si era adulta o recién nacida. Con respecto a la segunda mitad del siglo; tomando en consideración los bautismos, sobre un total de 7.146 registros, tenemos que esclavos eran 241 , es decir, el $3,37 \%$ del conjunto de bautizados en las dos parroquias de Mérida, y de ellos conocemos la identidad de 26 esclavos que se bautizaron adultos, de los cuales 16 eran varones y 10 mujeres, por tanto los bautizados

28 J. A. Ballesteros DIEZ: «Bautismo e historia social en Mérida a principios del siglo XVI». Revista de Estudios Extremeños, Tomo LVII, n. ${ }^{\circ}$ II, (2001), pp. 647-659. «Bautismos, confirmaciones y matrimonios en la historia social de Mérida en la segunda mitad del siglo XVI». Revista de Estudios Extremeños, Tomo LVIII, n. III, (2002), pp. 941-989. «Natalidad, nupcialidad y fecundidad en Mérida durante el siglo XVI» Espacio, Tiempo y Forma. Sección IV, n. ${ }^{\circ}$ 15, (2002), pp. 11-34. 
ya nacidos como esclavos eran 215 (el 3'01\%), y sus madres eran 152, lo que nos da una razón de hijos por madre de 1'42, teniendo en cuenta que se habían producido dos partos dobles por estas madres, de las cuales, la más prolífica fue María López, de la que se registran 5 hijos; esta esclava era propiedad de Marina Ortiz, viuda; con 4 hijos aparece Elvira, una esclava de Rodrigo de Cárdenas; Isabel, esclava del doctor Triana; Cecilia, esclava de Luis del Saz; y María de Solís, esclava de Bernardino de Solís.

En los registros se computan en total 231 esclavos con propietario identificado, y 10 en los que no se detalla, solamente se expresa la condición social esclava; la distribución del número de esclavos por propietarios era la siguiente:

Distribución de la propiedad de esclavos en Mérida

\begin{tabular}{|c|c|}
\hline Tipo de propietario & Número de propietarios \\
\hline - Con 1 esclavo & $80\left(61^{\prime} 5 \%\right)$ \\
- Con 2 esclavos & $29\left(22^{\prime} 3 \%\right)$ \\
- Con 3 esclavos & $7\left(5^{\prime}{ }^{\prime} \%\right)$ \\
- Con 4 esclavos & $8\left(6^{\prime} 2 \%\right)$ \\
- Con 5 esclavos & $5\left(3^{\prime} 8 \%\right.$ \\
- Con 10 esclavos & $1\left(0^{\prime} 8 \%\right.$ \\
\hline 231 esclavos & 130 propietarios \\
\hline
\end{tabular}

Entre los propietarios de esclavos se encuentran, lógicamente, los personajes y miembros de familias poderosas, como los Gobernadores de la Provincia de León de la Orden de Santiago, con residencia en Mérida, como Melchor Pérez de la Torre $(1559,1571)$, Duarte de Alvina (1574), Pedro Aboz Enríquez (1582) y Melchor de Brizuela (1593). También Rodrigo de Cárdenas, el propietario de 10 esclavos, descendiente del último maestre de la Orden de Santiago. Igualmente aparecen entre los propietarios numerosos clérigos, como Fernando de Arévalo, Alonso González de Arévalo, Bartolomé Pérez, Alonso Macías, Felipe González, Bartolomé Rodríguez, Pedro Rodríguez Capillas, Juan Enriquez de Guzmán, Francisco Rodríguez Mostaza, Francisco de Campo y Pedro López, también había una esclava para la monja Leonor de Sotomayor.

La relación nominal de los propietarios de esclavos de Mérida es la siguiente: Agustín Maldonado (Contador), Alonso de Contreras, Alonso de Monroy, Alonso de Sotomayor, Alonso Gómez (Bachiller), Alonso González de Arévalo (Clérigo), Alonso Halcón, Alonso Hernández (Regidor), Alonso Macías del Romas, Alonso Moreno Dalva, Ambrosio Hernández, Anasos Romero (Licenciado, Alcalde Mayor), Antonio Hernández (Labrador), Arévalo (Bachiller), Francisco de Almaraz, Bartolomé Pérez (Cura), Bartolomé Rodríguez (Clérigo), Bautista Carrión, Becerra (Ba- 
chiller), Bernardino de Solís, Briales (Licenciado), Cabezas (Bachiller), Pero Rodríguez Capillas (Licenciado), catalina Gonçalez (la perulera), Contreras (de Mirandilla), Cristóbal de Orellana, Diego de Ocampo de Figueroa, Diego Lorenzo, Diego Macías Romero, Diego Mateos (Mercader), Mexía (Doctor), Nieto (Doctor), Triana (Doctor), Duarte de Alvina (Licenciado, Gobernandor), Erevias, Esteban Martín (Regidor), Francisco López y Mencía Vaz, Felipe Gonçalez (Licenciado), Fernando de Arévalo, Fernando de Céspedes, Fernando de Toledo, Fernando Pantoja, Fernando Pérez de Vargas, Francisca de Aller, Francisca Gómez, Francisco de Cabranes, Francisco de Campo (Clérigo), Francisco García (Licenciado), Francisco Malaver, Francisco Ortiz (Contador), Francisco Rodríguez Brudo, Francisco Rodríguez Mostaza, Francisco Sánchez (Sombrerero), Francisco Solano, Francisco Zimbrón, García de Vargas, García López (Mercader), García Martín (Regidor), García Sánchez, Gonçalo Flores (Contador de la Mesa Maestral), Gonçalo Martínez, Gonçalo Montero, Gonçalo Sánchez Galindo, Guillermo Arias (Alguacil), Hernán de Campo de Alvarado, Hernán Sánchez Aguilar, Hernando de la Vera (Alcalde), Isabel Rodríguez (Viuda), J. Enríquez de Guzmán (Cura), Jerónimo de Ocampo, Juan de Ayala (Regidor), Juan de Baena, Juan de Chaves, Juan de Contreras, Juan de Sotomayor, Juan de Tovar, Juan de Vargas, Juan de Vera, Juan Fernández Collado, Juan Gutiérrez Céspedes, Juan Halcón, Juan López Morales, Juan Lorenzo, Juan Macías, Juan Macías de Castro, Juan Ramírez, Juan Sánchez (Boticario), Juan Zimbrón de Saavedra, Juana Gonçalez, Lázaro del Águila (Fiel y Regidor), Leonor de Sotomayor (Monja), Lope Mexía, Luis del Saz, Luis de Torres, Luisa López, María Gonçalez, Marina Ortiz (Viuda), Martín López, Martín Rol (Regidor), Mayor Rodríguez (Viuda), Melchor Álvarez (Mercader), Melchor de Brizuela (Gobernador), Melchor Pérez de Torres (Gobernador), Mencía Alonso, Mencía Vaz, Miguel Sánchez (Panadero), Pedro Ruiz de Sobremonte, Pero Sánchez Tejado, Pero Avoz Enríquez (Licenciado, Gobernador), Pero de Cipegómez (Licenciado), Pero Gonçalez (Licenciado), Pero Gutiérrez, Pero López (Clérigo), Pero Macías, Pero Mendez, Pero Messía de Prado, Pero Rodríguez Sobremonte, Pero Vazquez, Rodrigo de Cárdenas, Rodrigo de Vera, Rodrigo Díaz, Rodrigo Gutiérrez de Céspedes, Sahavedra (Licenciado), Sánchez (Bachiller), Serván do Campo, Serván López, Serván López Mahugo y María de Manos Alvas, Teresa (Doña), Tristán de Morales, Villalobos y Pedro Sánchez Galindo.

La posesión de esclavos, con un número de propietarios tan elevado, nos muestra, por una parte, la extensión del esclavismo dentro de la sociedad del Quinientos castellano, y, de otro lado, que no era exclusiva de los poderosos y altos eclesiásticos, sino que se encontraba muy repartida entre la sociedad, y así vemos que entre los propietarios se cuentan boticarios, sombrereros, mercaderes, viudas, labradores, mesoneros, panaderos, lo que configura un amplio espectro social.

El bautismo de esclavos adultos nos da testimonio de que la población de esclavos no sólo se mantenía por reproducción natural de las madres esclavas, es decir, por crecimiento vegetativo, sino que se incrementaba por compra u otro tipo de transmisión. 
Son muy escasas las referencias que se hacen de las razas de los esclavos, solamente se detallan en pocos casos, como el de Juan, negro, del Doctor Triana (1574); Juan, moro adulto, que pertenecía a Hernando de la Vera (1568); Francisco Zimbrón moreno, esclavo de Francisco Zimbrón (1586), María, negra, del bachiller Becerra (1567), e Isabel, negra también, de Pedro Macías; y Francisca Ximénez, negra, de la que no se reseña el propietario, como es también el caso de María Serasta, mora, o Isabel, negra tinta. En las actas de confirmaciones se menciona a un esclavo, Juan, cuyo propietario era Juan de Vargas, y del que se dice en el registro que «es hijo de la negra del Vicario» (1587).

También se registra un matrimonio entre esclavos, en 1598, entre Manuel y María de Ribera, propiedad ambos de Francisco Zimbrón, y por las actas bautismales conocemos los de Bartolomé y Felipa, esclavos de Catalina González, la perulera, en 1593, el de Manuel Nieto y Violante de Zimbrón, esclavos de Francisco Zimbrón, en 1560; y el de Antonio de Morales e Isabel Hernández, ambos esclavos negros tinto, sin propietario consignado.

Al tratar de confirmar si en Mérida se producía el mismo proceso que en Montijo, de que la esclava se preparaba para ser la nodriza de los hijos del propietario, cosa que no he podido determinar, si encontramos varios casos en los que tras el nacimiento del último hijo dentro de su matrimonio por parte de los propietarios, aparecen sucesivos nacimientos de hijos de alguna esclava, como son los casos de Melchor Álvarez, casado con Ana Xuarez, y con hijos nacidos entre 1581 y 1588, cuya esclava Catalina tuvo tres hijos, todos de padre desconocido, nacidos respectivamente el 21 de septiembre de 1589, el 22 de febrero de 1592 y 24 de enero de 1594, y al primero de los cuales, una niña, se le puso por nombre Melchora. Otro fue Serván de Ocampo, Regidor, que dejó de tener hijos en 1588, y su esclava Juana de Ocampo tuvo a Jerónimo en 1589 y a Francisco en 1596. También Bernardino de Solís, dejó de tener hijos en 1586, y de su esclava María de Solís se registran alumbramientos en 1591, 1494, 1595 y 1598. Igual sucede con Juan Ramírez y su esclava Ana Macías. Igualmente aparecen hijos de una misma esclava cuyos propietarios no han tenido descendencia en sus matrimonios.

De libertos tenemos pocas referencias, solamente cuando en 1598 se bautiza en la parroquia de Santa Olalla a una hija de «Isabel, esclava que fue del licenciado Briales, libre»; y también conocemos el caso de Bartolomé de la Cruz, esclavo del licenciado Bartolomé de Manos Albas, teniente de cura en la parroquia de Santa María; este esclavo compró su libertad y profesó en la Orden de San Francisco, murió hacia 1632.

\section{CONCLUSIONES}

Es evidente en este bosquejo que presentamos sobre la extensión de la esclavitud en Extremadura, que era un hecho generalizado en todo el territorio, aun- 
que con una notable diferencia de densidad de unos lugares a otros, pues si recopilamos algunos de los datos ofrecidos en las páginas precedentes, relativos al porcentaje de esclavos bautizados o confirmados sobre el total de los registrados en tales sacramentos, tenemos los siguientes porcentajes

- Badajoz: 1'2\%

- Almendralejo: 3’39\%

- La Fuente del Maestre: 2'94\%

- Llerena: 7'64\%

- Cáceres: 1'62\%

- Mérida: 3'37\%

Aunque estas cuantías no alcanzan la que Domínguez Ortiz estima para Sevilla, como señalamos anteriormente, entre el 6 y el $7 \%$ de la población, si podemos estimar que en estas de Extremadura son del orden de la mitad, salvo en el caso de Llerena, la localidad por cierto más próxima a Sevilla de todas las citadas. Porcentajes pequeños, correspondientes a unos grupos sociales minoritarios, carentes de presencia social y de protagonismo, en muchos casos con desprecio de su propia identidad como personas al negárseles hasta su nombre en los registros que conocemos, pero personas que formaban parte de unos entramados familiares y cumplían misiones cuya importancia vital no se puede soslayar, bien fueran como nodrizas, o como madres, aparte de otras tareas que pudieran efectuar en el ámbito doméstico. Por todo ello si injusta era su marginación dentro de la sociedad, también es injusto que por los historiadores se les preste tan poca atención, y habremos de recordar que si en el Derecho romano esclavo era alguien que había sido despojado de su libertad contra naturaleza (Digesto, 1.1.4), y si posteriormente la esclavitud era aceptada como parte de la realidad social, también es cierto que se producía un cierto cuestionamiento de la esclavitud, lo que se evidenciaba en la aparición recurrente de argumentos justificativos, como eran los de la guerra justa, o simplemente el del respeto a la ley positiva, o el de la tradición cristiana del buen trato al esclavo. No se trata pues de hacer ahora un planteamiento moral, aunque cupiera dentro de algunos objetivos historiográficos, pero precisamente por la exigencia de rigor para conocer, entender y explicar nuestra sociedad del siglo $\mathrm{XVI}$, es por lo que presentamos estas realidades al objeto de que, por una parte, las veamos como lo que representaban, es decir, como partes reales de la sociedad, y, de otro lado, llamar la atención sobre el enorme vacío que tenemos de este dramático tema en los trabajos sobre nuestra historia. 